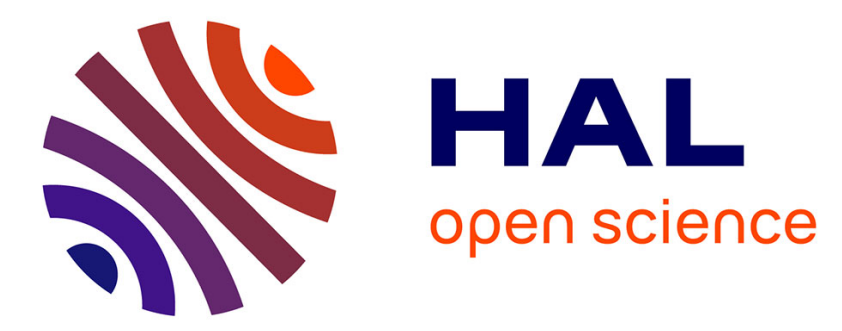

\title{
III-V-semiconductor vertically-coupled whispering-gallery mode resonators made by selective lateral oxidation
}

Stéphane Calvez, Gael Lafleur, Clément Arlotti, Alexandre Larrue, Pierre-François Calmon, Alexandre Arnoult, Guilhem Almuneau, Olivier Gauthier-Lafaye

\section{To cite this version:}

Stéphane Calvez, Gael Lafleur, Clément Arlotti, Alexandre Larrue, Pierre-François Calmon, et al.. III-V-semiconductor vertically-coupled whispering-gallery mode resonators made by selective lateral oxidation. SPIE LASE, Feb 2016, San Francisco, United States. 10.1117/12.2210968 . hal-01768290

\author{
HAL Id: hal-01768290 \\ https://hal.laas.fr/hal-01768290
}

Submitted on 3 May 2018

HAL is a multi-disciplinary open access archive for the deposit and dissemination of scientific research documents, whether they are published or not. The documents may come from teaching and research institutions in France or abroad, or from public or private research centers.
L'archive ouverte pluridisciplinaire HAL, est destinée au dépôt et à la diffusion de documents scientifiques de niveau recherche, publiés ou non, émanant des établissements d'enseignement et de recherche français ou étrangers, des laboratoires publics ou privés. 
Return to the Manage Active Submissions page at http://spie.org/submissions/tasks.aspx and approve or disapprove this submission. Your manuscript will not be published without this approval. Please contact author_help@spie.org with any questions or concerns.

\title{
III-V-semiconductor vertically-coupled whispering-gallery mode resonators made by selective lateral oxidation
}

\author{
S. Calvez , G. Lafleur, C. Arlotti, A. Larrue, P.-F. Calmon, A. Arnoult, G. Almuneau \\ and O. Gauthier-Lafaye \\ CNRS, LAAS, 7 avenue du colonel Roche, F-31400 Toulouse, France \\ Univ. de Toulouse, UPS, LAAS, F-31400 Toulouse, France
}

\begin{abstract}
Integrated whispering-gallery mode resonators are attractive devices which have found applications as selective filters, low-threshold lasers, high-speed modulators, high-sensitivity sensors and even as nonlinear converters. Their performance is governed by the level of detrimental (scattering, bulk, bending) loss incurred and the usable loss represented by the coupling rate between the resonator and its access waveguide. Practically, the latter parameter can be more accurately controlled when the resonator lies above the access waveguide, in other words, when the device uses a vertical integration scheme. So far, when using such an integration technique, the process involved a rather technically challenging step being either a planarization or a substrate transfer step.

In this presentation, we propose and demonstrate an alternative method to fabricate vertically-coupled whispering-gallery mode resonators on III-V semiconductor epitaxial structures which has the benefit of being planarization-free and performed as single-side top-down process. The approach relies on a selective lateral thermal oxidation of aluminum-rich AlGaAs layers to define the buried access waveguide and enhance the vertical confinement of the whispering-gallery mode into the resonator. As a first experimental proof-of-principle of this approach, $75 \mu$ m-diameter micro-disk devices exhibiting quality factor reaching $\sim 4500$ have been successfully made.
\end{abstract}

Keywords: resonator, disk, whispering gallery mode, integration, oxidation, AlOx, GaAs

\section{INTRODUCTION}

Integrated whispering-gallery mode resonators are compact devices which can exhibit greatly enhanced intra-cavity fields at selected wavelengths, the exploitation of which makes them attractive for applications such as narrowbandwidth filters, low-threshold lasers, high-speed modulators, high-sensitivity sensors or low-power nonlinear converters ${ }^{1,2,3}$. As indicated above, their usefulness is essentially governed by the ability to obtain high quality factors. To do so, it is necessary to simultaneously minimize the amount of detrimental (scattering, bulk, bending) loss in the resonator and obtain the "so-called" critical coupling condition where the latter loss level is equal to the coupling rate between the resonator and its access waveguide(s). Since the resonator in/out coupling is commonly done in the form of an evanescent coupling scheme, it is easier to meet the latter condition with the technological approach which offers the most tolerant and controllable process. It turns out to be when the resonator lies above the access waveguide or, in other words, when the device is made by vertical integration ${ }^{4,5}$. To implement such geometry in practice, the fabrication of a buried (access) waveguide with a planar top surface is needed. This task happens to be technologically complex, typically requiring a demanding technological step such as a planarization step ${ }^{6,7}$ or a substrate transfer $^{8}$.

In this paper, following our recent demonstration ${ }^{9}$, we present a technologically simpler method to fabricate verticallycoupled micro-disk resonators in III-V semiconductors based on the use of a selective lateral oxidation step to define the buried access waveguide. 


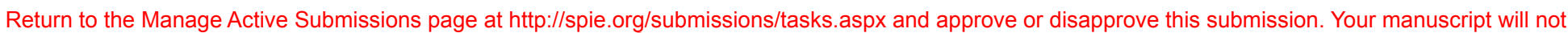
be published without this approval. Please contact author_help@spie.org with any questions or concerns.

\section{DESIGN}

A schematic representation of a vertically-coupled microdisk under study is shown in Figure 1.

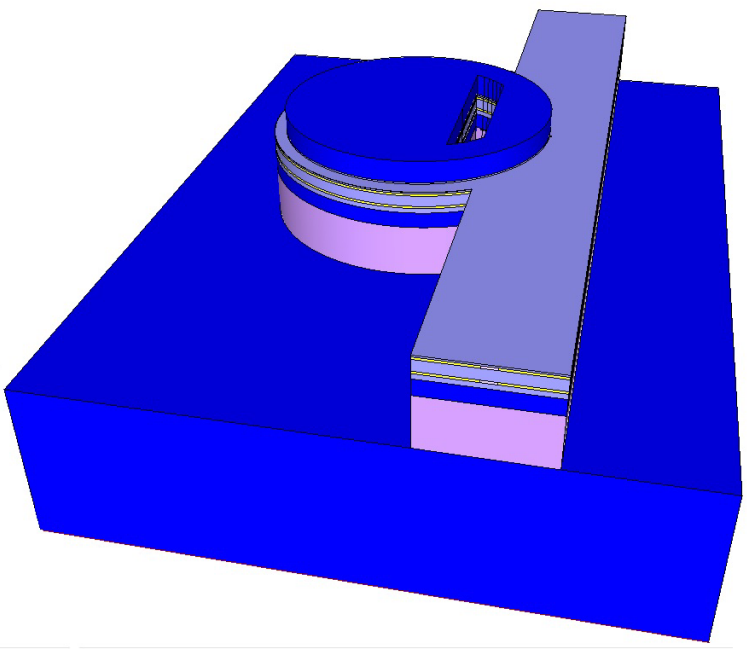

Figure 1. Device schematic (dark blue: GaAs - light blue $\mathrm{Al}_{0.3} \mathrm{Ga}_{0.7} \mathrm{As}$ - light purple $\mathrm{Al}_{0.6} \mathrm{Ga}_{0.4} \mathrm{As}$ - yellow: $\mathrm{AlOx}$ )

The layered vertical structure is composed of an air/GaAs/ $/ \mathrm{Al}_{0.3} \mathrm{Ga}_{0.7} \mathrm{As} / \mathrm{Al}_{0.98} \mathrm{Ga}_{0.02} \mathrm{As}_{\mathrm{s}} / \mathrm{Al}_{0.3} \mathrm{Ga}_{0.7} \mathrm{As}$ resonator waveguide on top of an AlOx confined buried access waveguide. The access waveguide stack is an asymmetric $\mathrm{Al}_{0.3} \mathrm{Ga}_{0.7} \mathrm{As} / \mathrm{GaAs} / \mathrm{Al}_{0.6} \mathrm{Ga}_{0.4} \mathrm{As}$ waveguide with an $\mathrm{Al}_{0.98} \mathrm{Ga}_{0.02} \mathrm{As}$ layer inserted in the $\mathrm{Al}_{0.3} \mathrm{Ga}_{0.7} \mathrm{As}$ upper cladding. The high-aluminum-containing layers will be selectively transformed into AlOx to form the waveguide aperture and enhance the vertical confinement of the resonator modes. The thickness of the GaAs cores $(680 \mathrm{~nm}$ for the resonator and $400 \mathrm{~nm}$ for the access waveguide) were selected to obtain identical slab waveguide effective indexes. The chosen $330 \mathrm{~nm}$ $\mathrm{Al}_{0.3} \mathrm{Ga}_{0.7} \mathrm{As}$ separation lead to the resonator supermode of the coupled slab waveguides to present a $1 \%$ (respectively $6.2 \%$ ) intensity overlap with the core of the access waveguide slab when the $\mathrm{Al}_{0.98} \mathrm{Ga}_{0.02} \mathrm{As}$ layers are considered to be oxidized (respectively unoxidized).

The position $(150 \mathrm{~nm})$ and width of the AlOx aperture were chosen to achieve $>3-\mu \mathrm{m}$-wide singlemode waveguides to facilitate cleaved-facet injection and to be compatible with the $(\sim 1-\mu \mathrm{m}-)$ spatial resolution of oxidation furnace monitoring system ${ }^{10}$. Figure 2 shows the effective index contrast between the oxidized and unoxidized regions and the maximum width of the aperture for singlemode operation as a function of the separation between the oxide layer and the waveguide core.
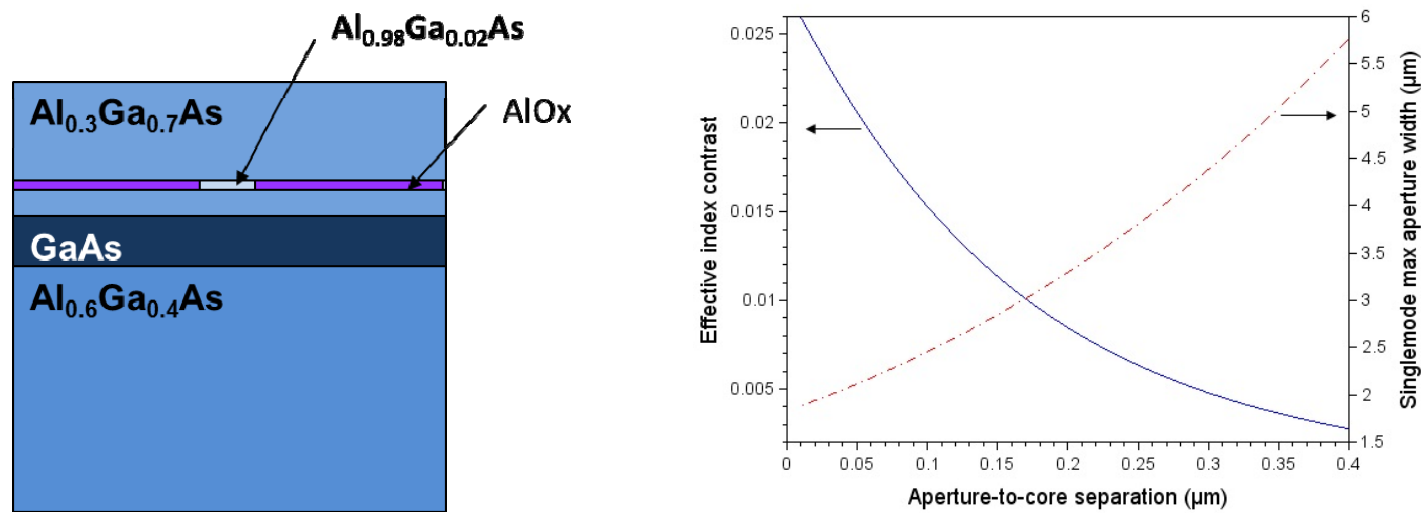

Figure 2. Access waveguide cross-section diagram and key characteristics (at a wavelength of $1.55 \mu \mathrm{m}$ ). 
Return to the Manage Active Submissions page at http://spie.org/submissions/tasks.aspx and approve or disapprove this submission. Your manuscript will not be published without this approval. Please contact author_help@spie.org with any questions or concerns.

For a separation of $150 \mathrm{~nm}$, further waveguide calculations carried out using 2x1D effective index and a vectorial mode solver (WGModes) ${ }^{11}$ show that the waveguide can be considered to remain singlemode up to a aperture width of $\sim 3.7 \mu \mathrm{m}$.
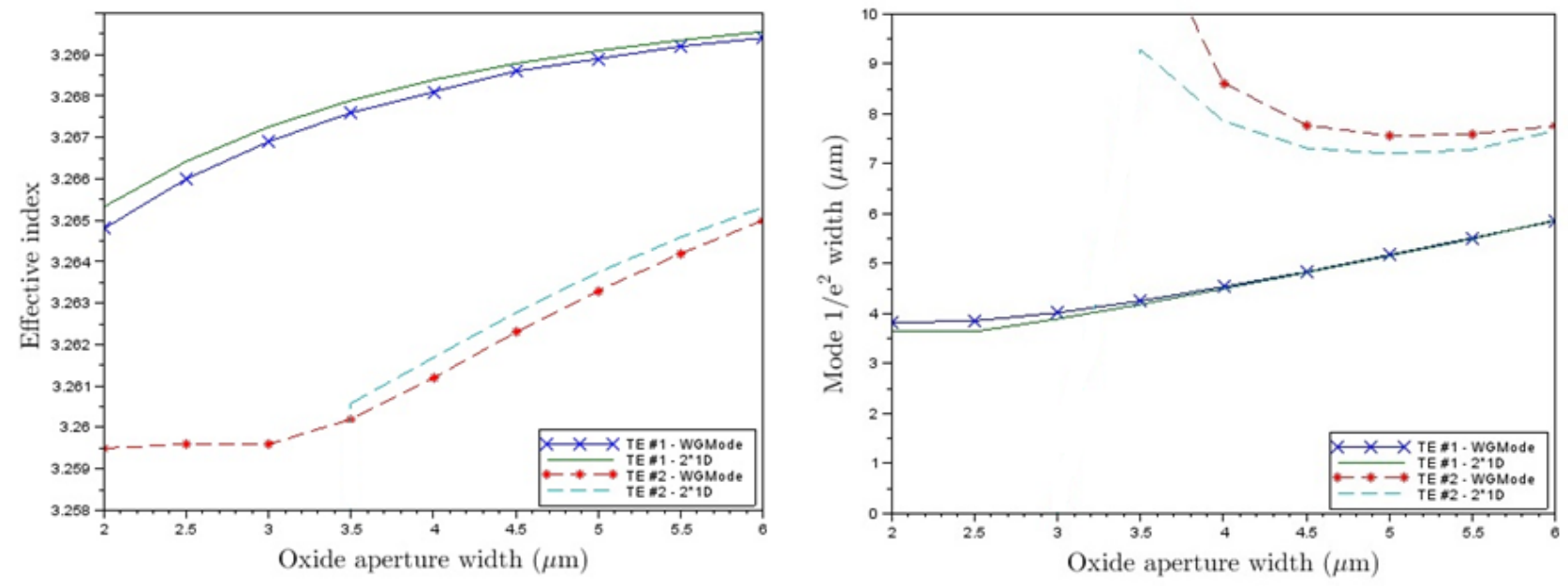

Figure 3. Effective indexes and mode lateral widths at a wavelength of $1.55 \mu \mathrm{m}$ for the first two TE-polarized modes that the oxide-apertured waveguide might support.

Neglecting the access slab waveguide, the evolution of the resonator mode effective index as a function the microdisk diameter was also evaluated using a cylindrical geometry and a vectorial finite-difference mode solver (WGMS3D) ${ }^{12}$. Figure 4 shows, as expected, that the resonator effective index reduces as the diameter decreases. This variation also influences the coupling between the resonator and the access waveguide effective index $\left(\mathrm{n}_{\text {access }} \sim 3.267\right)$ as the coupling beat length shrinks from $28.7 \mu \mathrm{m}$ at a diameter of $400 \mu \mathrm{m}$ down to $6.6 \mu \mathrm{m}$ for a $50-\mu \mathrm{m}$-diameter microdisk.

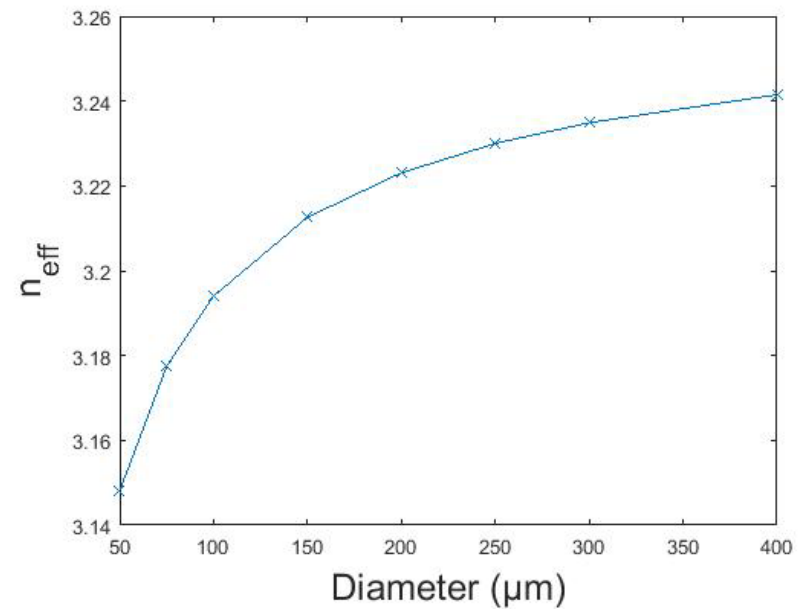

Figure 4. Resonator mode effective index at a wavelength of $1.55 \mu \mathrm{m}$ 
Return to the Manage Active Submissions page at http://spie.org/submissions/tasks.aspx and approve or disapprove this submission. Your manuscript will not be published without this approval. Please contact author_help@spie.org with any questions or concerns.

\section{FABRICATION}

The above-described layer structure was grown by molecular beam epitaxy on a standard (001) GaAs wafer. The devices were then fabricated using two lithographic and etching steps permitting the successive definition of the access guides and the resonators. As shown in Figure 5, the subsequent wet oxidation of both $\mathrm{Al}_{0.98} \mathrm{Ga}_{0.02} \mathrm{As}$ layers was performed at a rate of $\sim 0.12 \mu \mathrm{m} / \mathrm{min}$ in a custom furnace under optical monitoring and stopped after an oxidation extent of $\sim 14 \mu \mathrm{m}$ leading to $3.7-\mu \mathrm{m}$-wide-apertured buried access waveguides. The wafer was then thinned down to $\sim 150 \mu \mathrm{m}$, cleaved into samples which were subsequently mounted on custom Si-based sub-mounts. An image of a resulting microdisk is shown in Figure 6.

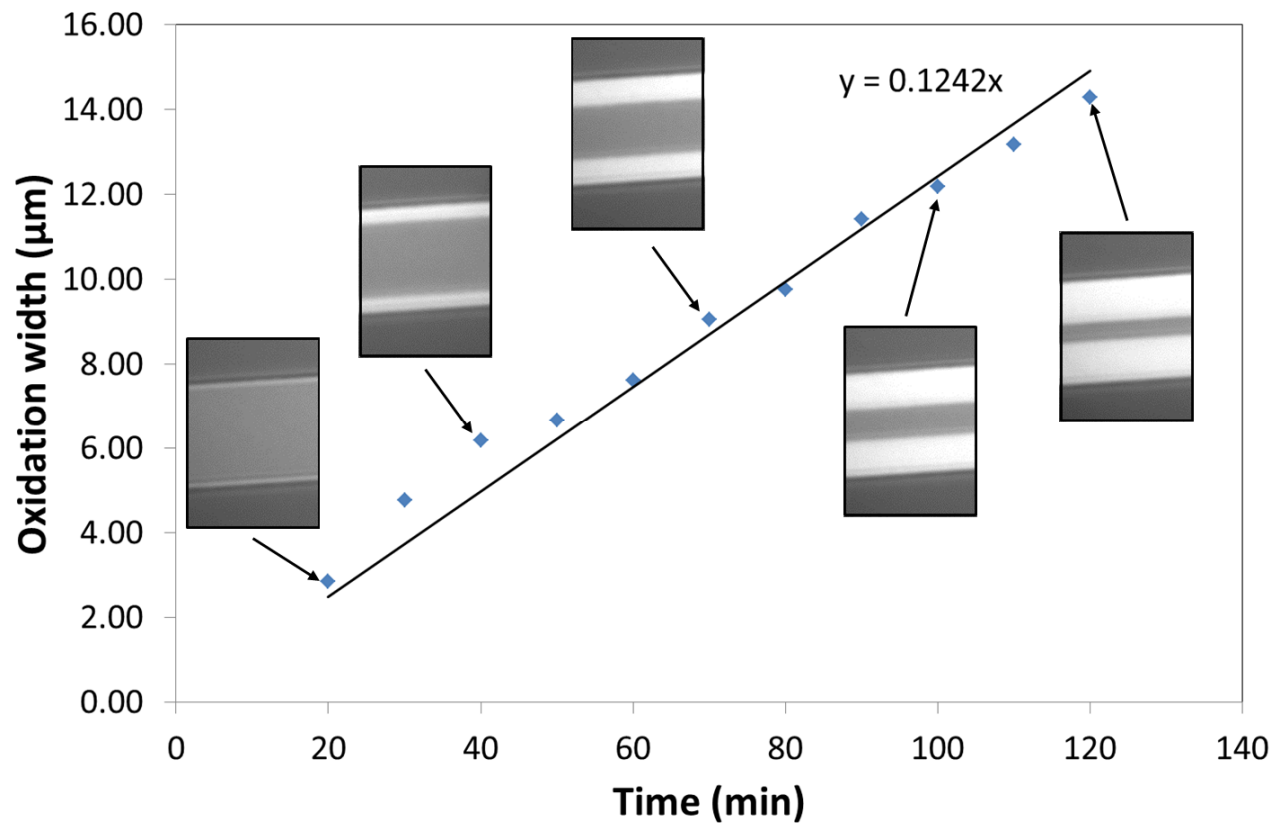

Figure 5. Evolution of the lateral extent of the oxide (white part on the images) as monitored by infrared reflectometry. The width of the mesa is $32 \mu \mathrm{m}$.

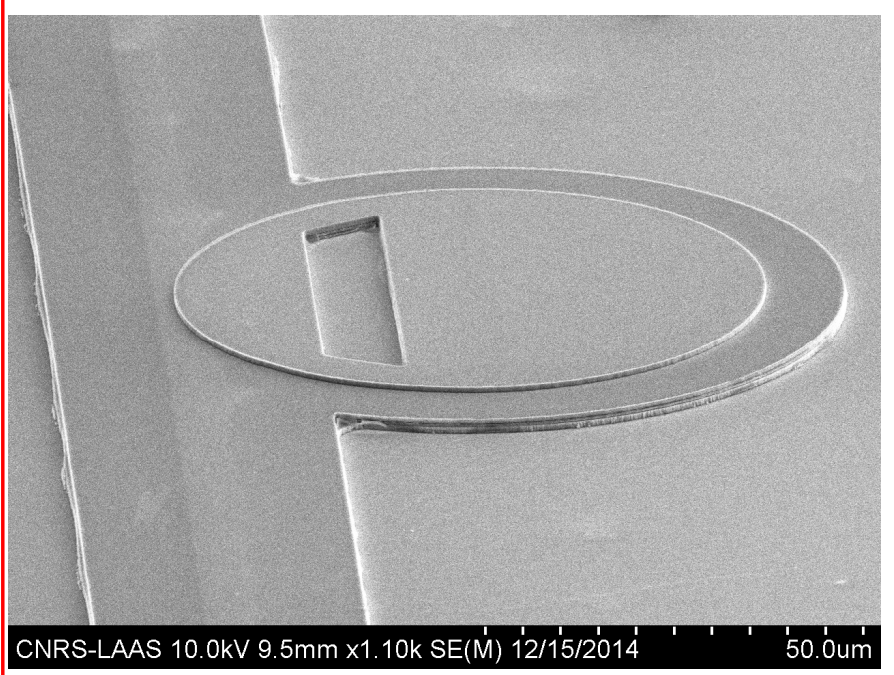

Figure 6. SEM picture of a $75-\mu \mathrm{m}$-diameter microdisk. 
Return to the Manage Active Submissions page at http://spie.org/submissions/tasks.aspx and approve or disapprove this submission. Your manuscript will not be published without this approval. Please contact author_help@spie.org with any questions or concerns.

\section{CHARACTERISATION AND ANALYSIS}

The mounted devices were characterized using the setup shown in Figure 7. The transmission characteristics were recorded using a step-tunable laser with central wavelength of $1.6 \mu \mathrm{m}$, a $10 \mathrm{pm}$ spectral resolution and a $100 \mathrm{kHz}$ linewidth. Figure 7 (right) shows the measured transmission characteristic of a 75 - $\mu \mathrm{m}$-diameter microdisk over one free spectral range. The intensity contrast $\left(\mathrm{c}=\left(\mathrm{I}_{\max }-\mathrm{I}_{\min }\right) /(\operatorname{Imax}+\operatorname{Imin})\right)$ and loaded $\mathrm{Q}$-factor $(\mathrm{Q}=\lambda / \Delta \lambda)$ are respectively measured to be 0.403 and 4450 .
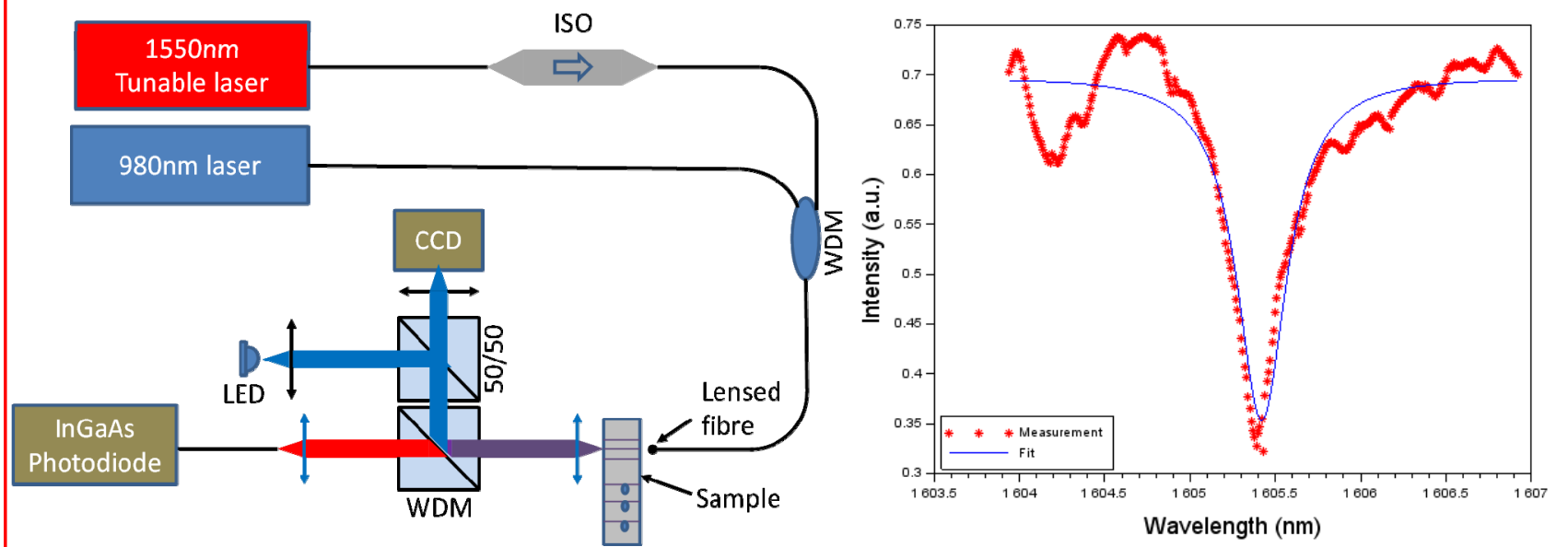

Figure 7. Characterization setup and typical close-to-resonance response of a $75 \mu \mathrm{m}$-diameter microdisk.

To extract more meaningful parameters, namely the amplitude coupling coefficient $(\kappa)$ and the intensity absorption coefficient $(\alpha)$, maps of the contrast and $\mathrm{Q}$ factors were calculated using the general equation ${ }^{13}$ :

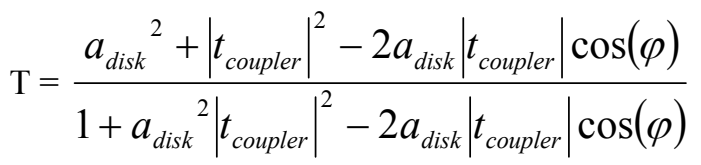

where $t_{\text {coupler }}$ is the amplitude transmission coefficient of the coupling region $\left(t_{\text {coupler }}=\left(1-\kappa^{2}\right)^{0.5}\right)$ and $\mathrm{a}_{\text {disk }}$ stands for the amplitude transmission coefficient $\left(\mathrm{a}_{\mathrm{disk}}=\exp (-\alpha \pi \mathrm{D} / 2)\right)$, and $\varphi$ corresponds to the phase accumulated over one round-trip along the resonator periphery.
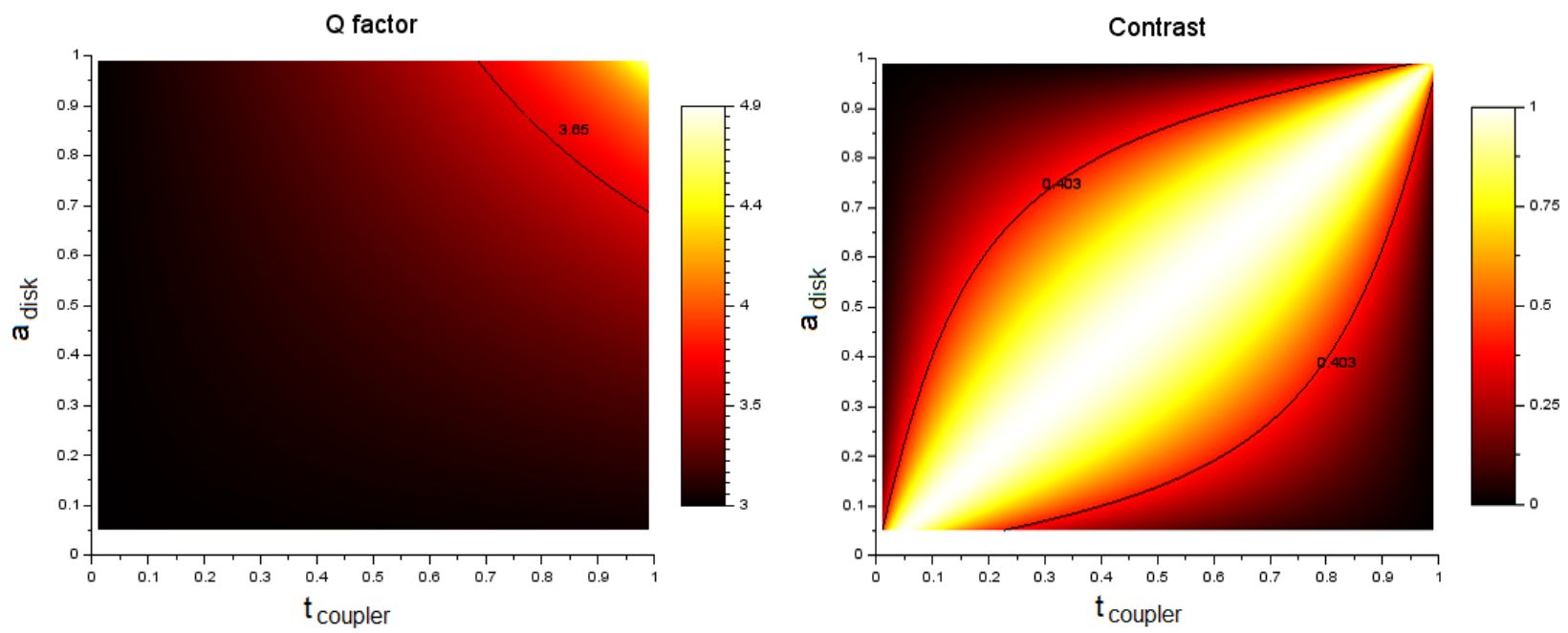

Figure 8. Calculated Q-factor (in log scale) and contrast maps for a $75-\mu \mathrm{m}$-diameter microdisk. 
Return to the Manage Active Submissions page at http://spie.org/submissions/tasks.aspx and approve or disapprove this submission. Your manuscript will not be published without this approval. Please contact author_help@spie.org with any questions or concerns.

As it can be readily seen from equation (1) and inferred from Figure 8 , two solutions $\left(\mathrm{t}_{\text {coupler }}, \mathrm{a}_{\mathrm{disk}}\right)=(0.72,0.93)$ and $\left(\mathrm{t}_{\text {coupler }}, \mathrm{a}_{\mathrm{disk}}\right)=(0.93,0.72)$ corresponding respectively to the over-coupled (low-loss) resonator $\left(\kappa=0.69, \alpha=6.2 \mathrm{~cm}^{-1}\right)$ and under-coupled (high-loss) resonator $\left(\kappa=0.37, \alpha=27.8 \mathrm{~cm}^{-1}\right)$ situations can provide a match to the above-mentioned characteristic values $(\mathrm{Q}=4450, \mathrm{c}=0.403)$. The measurements carried out to-date do not allow the discrimination between these two situations although experimental techniques exist to alleviate this undetermination ${ }^{14,15}$. Nevertheless, similar analysis was performed on devices with greater diameters (up to $300 \mu \mathrm{m}$ ) and the summary of the performance is provided in Figure 9.
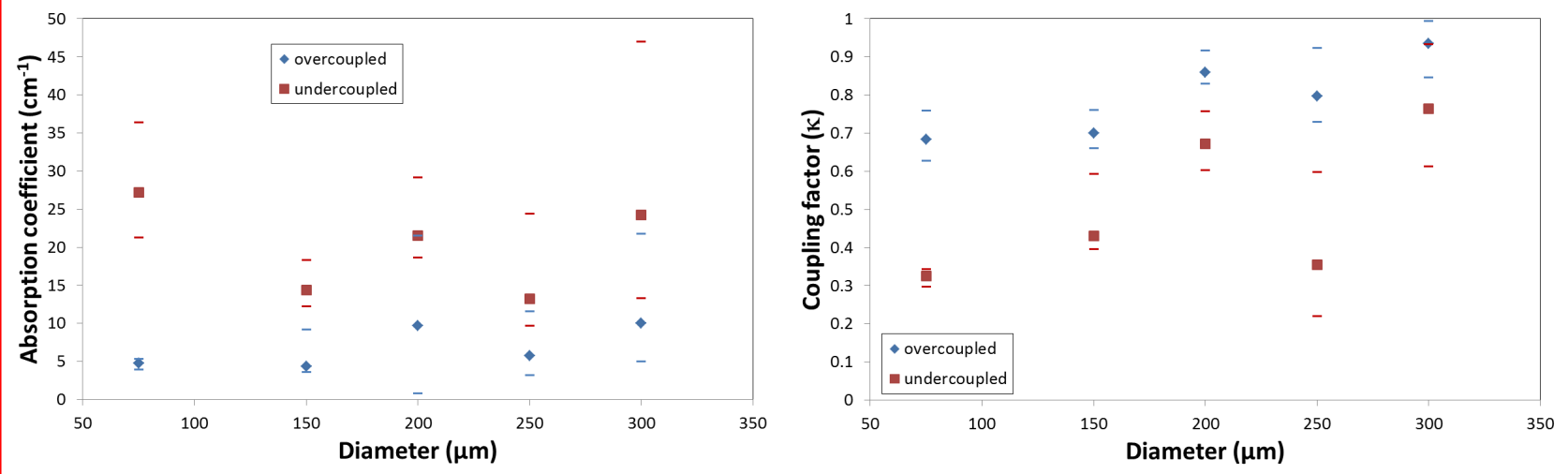

Figure 9. Calculated Q-factor and contrast maps for a 75- $\mu$ m-diameter microdisk.

With a view to understand the device performance limiting factors, the bending losses and substrate-leakage-like losses induced by the presence of the slab access waveguide were evaluated by vectorial finite-difference mode analysis. As shown in Figure 10, the substrate loss dominates with a value of $9.2 \mathrm{~cm}^{-1}$ (compounded with the bending loss) for a 75 - $\mu \mathrm{m}$-diameter microdisk rising to $15.0 \mathrm{~cm}^{-1}$ for $300 \mu \mathrm{m}$-diameter disks. This also suggests that, in spite of a relatively thin separation layer, the devices are operating in under-coupling regime, possibly because of the unfavorable effective index mismatch between the resonator and the access waveguide.

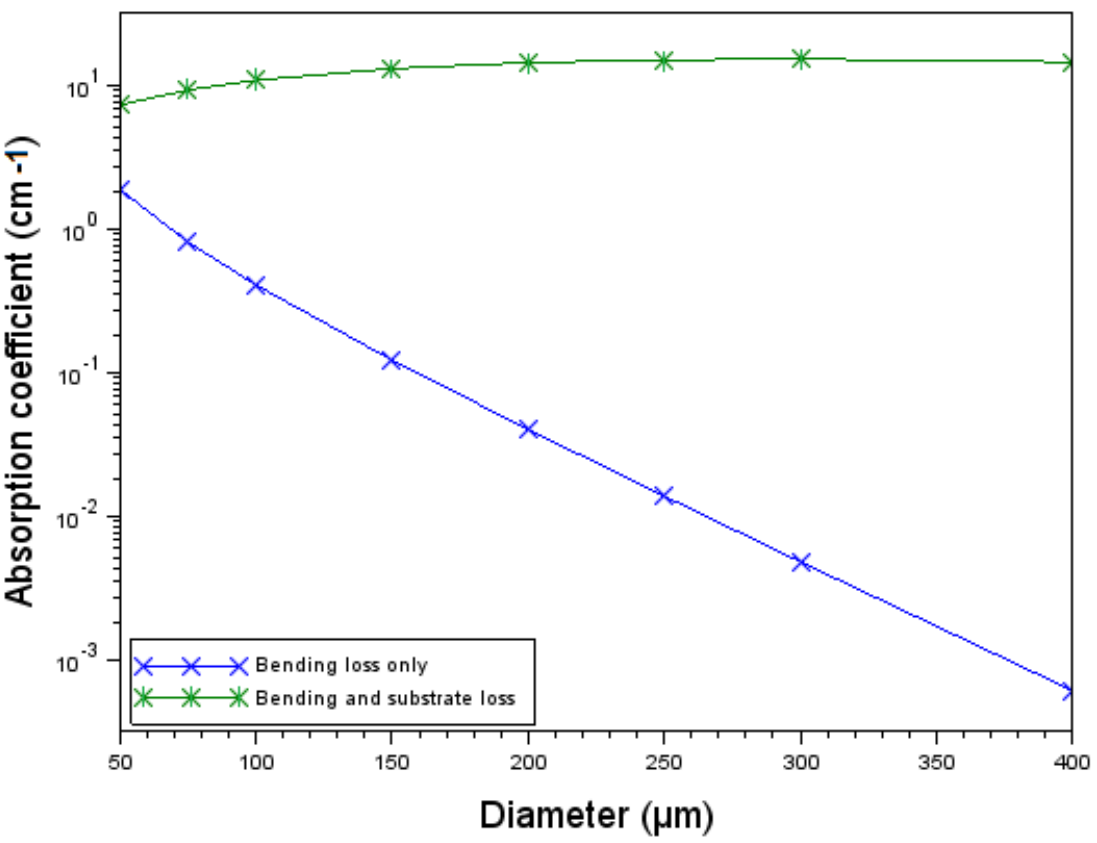

Figure 10. Calculated Q-factor and contrast maps for a $75 \mu \mathrm{m}$-diameter microdisk. 
Return to the Manage Active Submissions page at http://spie.org/submissions/tasks.aspx and approve or disapprove this submission. Your manuscript will not be published without this approval. Please contact author_help@spie.org with any questions or concerns.

\section{CONCLUSIONS}

A novel method exploiting selective lateral oxidation has been established to fabricate vertically-coupled whisperinggalery-mode resonators on III-V semiconductors. The first fabrication run lead to 75 - $\mu \mathrm{m}$-diameter microdisks with $\mathrm{Q}$ factor reaching 4450 at a wavelength of $\sim 1600 \mathrm{~nm}$. The performance of the current set of devices was identified to be limited by the leakage to the slab access waveguide. Future work will focus on the modification of the structure to reach higher Q-factors.

\section{ACKNOWLEDGEMENTS}

Clément Arlotti would like to acknowledge the Délégation Générale de l'Armement and the Centre National d'Etudes Spatiales for supporting his $\mathrm{PhD}$ studentship. The work was also partly supported by the Centre National d'Etudes Spatiales research Grant R et T: R-S13-LN-0001-025 and the French Renatech Network of cleanroom facilities.

\section{REFERENCES}

[1] Matsko, A. B.., Ilchenko, V. S., "Optical resonators with whispering gallery modes I: basics,” IEEE J Sel Top Quantum Electron 12(1), 3-14 (2006).

[2] Feng, S., Lei, T., Chen, H., Cai, H., Luo, X.., Poon, A. W., "Silicon photonics: from a microresonator perspective," Laser Photonics Rev. 6(2), 145-177 (2012).

[3] Ward, J.., Benson, O., "WGM microresonators: sensing, lasing and fundamental optics with microspheres," Laser Photonics Rev. 5(4), 553-570 (2011).

[4] Chyng Wen Tee., Williams, K. A., Penty, R. V.., White, I. H., "Fabrication-tolerant active-passive integration scheme for vertically coupled microring resonator," IEEE J. Sel. Top. Quantum Electron. 12(1), 108-116 (2006).

[5] Ghulinyan, M., Ramiro-Manzano, F., Prtljaga, N., Guider, R., Carusotto, I., Pitanti, A., Pucker, G.., Pavesi, L., "Oscillatory Vertical Coupling between a Whispering-Gallery Resonator and a Bus Waveguide," Phys. Rev. Lett. 110(16), 163901 (2013).

[6] Suzuki, S., Shuto, K.., Hibino, Y., "Integrated-optic ring resonators with two stacked layers of silica waveguide on Si,” Photonics Technol. Lett. IEEE 4(11), 1256-1258 (1992).

[7] Ghulinyan, M., Guider, R., Pucker, G.., Pavesi, L., "Monolithic Whispering-Gallery Mode Resonators With Vertically Coupled Integrated Bus Waveguides," IEEE Photonics Technol. Lett. 23(16), 1166-1168 (2011).

[8] Absil, P. P., Hryniewicz, J. V., Little, B. E., Johnson, F. G., Ritter, K. J.., Ho, P.-T., "Vertically coupled microring resonators using polymer wafer bonding," Photonics Technol. Lett. IEEE 13(1), 49-51 (2001).

[9] Calvez, S., Lafleur, G., Larrue, A., Calmon, P.-F., Arnoult, A., Almuneau, G.., Gauthier-Lafaye, O., "Vertically Coupled Microdisk Resonators Using AlGaAs/AlOx Technology,” IEEE Photonics Technol. Lett. 27(9), 982-985 (2015).

[10] Almuneau, G., Bossuyt, R., Collière, P., Bouscayrol, L., Condé, M., Suarez, I., Bardinal, V.., Fontaine, C., "Realtime in situ monitoring of wet thermal oxidation for precise confinement in VCSELs," Semicond. Sci. Technol. 23(10), 105021 (2008).

[11] Fallahkhair, A. B., Li, K. S.., Murphy, T. E., "Vector Finite Difference Modesolver for Anisotropic Dielectric Waveguides," J. Light. Technol. 26(11), 1423-1431 (2008).

[12] Krause, M., "Finite-Difference Mode Solver for Curved Waveguides With Angled and Curved Dielectric Interfaces," J. Light. Technol. 29(5), 691-699 (2011).

[13] Yariv, A., "Universal relations for coupling of optical power between microresonators and dielectric waveguides," Electron. Lett. 36(4), 321-322 (2000).

[14] Lee, Y., Chen, W., Chen, D., Zeng, Y., Lu, H.., Yang, J., “A General Characterizing Method for Ring Resonators Based on Low Coherence Measurement," J. Light. Technol. 30(6), 846-852 (2012).

[15] Zhou, L., Sun, X., Xie, J., Zou, Z., Lu, L.., Chen, J., "Characterisation of microring resonator optical delay and its dependence on coupling gap using modulation phase-shift technique," Electron. Lett. 48(25), 1613-1614 (2012). 